\title{
LETRAMENTOS CONTEMPORÂNEOS: A ERRÁTICA EXPANSÃO DAS FORMAS DE REPRODUÇÃO E TRANSFORMAÇÃO SOCIAL NA ERA DA GLOBALIZAÇÃO RECENTE
}

\author{
Júlio Cesar Salles Boaventura* \\ Branca Falabella Fabrício**
}

\begin{abstract}
Resumo: Este trabalho tem como objeto de estudo as práticas contemporâneas de letramentos e seus efeitos sobre a produção do conhecimento e da vida social. Trata-se de uma discussão teórica sobre como a expansão das práticas de letramentos, advindas de diferentes loci de enunciação, pôs em xeque a produção de saberes e subjetividades legitimados pela modernidade. Explorando a literatura recente sobre modos contemporâneos de produção de sentido, constatamos que o uso subversivo das novas tecnologias da informação e da comunicação e as contíguas práticas de letramentos têm fomentado formas de ativismo em que performances identitárias de gênero, classe, raça e sexualidade se entrecruzam. Com base em tal fenômeno, argumentamos que a interseccionalidade perpassa agendas políticas, abrangendo, concomitantemente, demandas singulares e coletivas.
\end{abstract}

Palavras-chave: Letramentos. Contemporaneidade. Tecnologias. Ativismo político. Interseccionalidades.

Abstract: This paper focus on contemporary literacy practices and their effects on the construction of knowledge and social life. It's a theoretical discussion on how the expansion of literacy practices, which come from different enunciation loci, undermines the hegemonic models for the production of knowledge and subjectivities legitimized by modernity. Based on recent bibliographic research about contemporary ways of production of meaning, we have observed that the subversive usage of new information and communication technologies and contiguous literacy practices have fostered different forms of activism in which identity performances of gender, social class, race and sexuality intertwine. Based on this phenomenon, we argue that intersectionality impregnates political agendas that embrace, at the same time, singular and collective demands.

Keywords: Literacies. Contemporaneity. Technologies. Political activism. Intersectionality.

\section{Globalização: uma perspectiva a partir das margens}

A desintegração da URSS, o colapso dos países comunistas do Leste europeu e o abrupto fim de um mundo acomodado em uma estável bipolaridade político-ideológica não representaram simplesmente a vitória derradeira do capitalismo e - como alguns pensadores liberais apostaram - o fim da luta de classes e o fim da história (FUKUYAMA, 1992). O fim do "breve século XX", como assim o denominou o historiador Eric Hobsbawn (1994), e o fim do equilíbrio mundial tecido ao longo das quatro décadas de Guerra Fria vieram acompanhados da dramática e sub-reptícia dissolução das sociedades industriais modernas e do advento das sociedades contemporâneas em que novos atores, suas novas demandas e formas de atuação política passaram a compor um cenário global jamais imaginado pelas teorias sociais modernas.

O modo silencioso como as mudanças vem sendo processadas nesse novo mundo, sem grandes guerras ou revoluções e sem a dependência de decisões parlamentares ou governamentais, revela um tipo de dinâmica social em que todos nós, voluntariamente ou a contragosto, participamos a partir de debates ou conflitos que põe em xeque as certezas que a modernidade nos ensinou a crer. Não temos mais, por exemplo, a certeza de um progresso

\footnotetext{
* Doutorando do Programa Interdisciplinar de Linguística Aplicada da UFRJ. Endereço eletrônico: julioboaventura@ufrj.br

** Professora Associada do Programa Interdisciplinar de Linguística Aplicada da UFRJ. Endereço eletrônico: branca.falabella@pq.cnpq.br
} 
social ancorado pelo ilimitado progresso técnico-científico nem a confiança de que o estadonação possa restringir a ação voraz do mercado em seu território e garantir o emprego de seus habitantes. Além disso, os portos seguros da tradição moderna como a família, a Igreja e a comunidade local não dão mais conta das novas demandas sociais que surgem a reboque dos encontros e choques interculturais a que somos expostos diariamente por meio das novas tecnologias da informação e da comunicação. Esse cenário de insegurança é a um só tempo o resultado da falência da sociedade industrial e da emergência da sociedade de risco. Acerca da sociedade de risco, Beck (1995, p. 15) afirma que "este conceito designa uma fase no desenvolvimento da sociedade moderna, em que os riscos sociais, políticos, econômicos e individuais tendem cada vez mais a escapar das instituições para o controle e a proteção da sociedade industrial."

A transição da era industrial para a era do risco se processa no momento em que os efeitos da Revolução Industrial passam a ser considerados ameaças efetivas à humanidade. Nesse aspecto, o confronto entre as certezas da velha sociedade industrial e os riscos inesperados e incontroláveis que produz constitui um movimento autônomo e inexorável da modernidade de superação de seus próprios fundamentos denominado por Beck como modernização da modernidade ou modernização reflexiva. De acordo com esse autor,

Modernização reflexiva significa autoconfrontação com os efeitos da sociedade de risco que não podem ser tratados e assimilados no sistema da sociedade industrial - como está avaliado pelos padrões institucionais desta última. $\mathrm{O}$ fato de esta própria constelação poder mais tarde, em um segundo estágio, vir a se tornar objeto de reflexão (pública, política e científica) não deve obscurecer o mecanismo não refletido e quase autônomo da transição: é exatamente a abstração que produz e proporciona realidade à sociedade de risco. (BECK, 1995, p. 16-17).

No presente estágio da modernidade - e em outros momentos da história - os riscos e o dimensionamento dos mesmos são sempre construções dos imaginários coletivos que escapam à determinação e ao controle da razão instrumental. Contudo, na mesma medida em que são pós-racionais, os riscos surgem e se reproduzem a partir do excesso de racionalismo em uma sociedade pluralista e racional. Nas sociedades do controle e da ordem como as da era industrial e pós-industrial, a expansão dos mecanismos de governo acabou por produzir o oposto do que se esperava deles: a multiplicação da desordem, do descontrole e dos riscos. A falência dos modelos de segurança das instituições políticas modernas (governos, partidos políticos, parlamentos, sindicatos, etc.) e do próprio mercado - visto que novos riscos não são previstos ou cobertos pelas apólices de seguros - trouxe aos cidadãos comuns a necessidade de produzir racionalizações sobre os mais variados temas em busca de soluções autônomas para os mais variados problemas. Em suma, a multiplicação dos riscos - efeito colateral e inelutável da modernização da modernidade - implica a proliferação das formas de atribuir significado às realidades e, consequentemente, a proliferação dos embates ideológicos, culturais e políticos.

Sob esse cenário de proliferação de antagonismos de toda sorte, é oportuno afirmar que "a sociedade de risco é tendencialmente também uma sociedade autocrítica" (BECK, 1995, p. 22) cujos membros de distintos campos de saber e de distintas cosmologias confrontam suas perspectivas acerca dos diferentes riscos. Esse caráter autocrítico e de consequências imprevisíveis sobrepõe-se ao tradicional sistema político de cartas marcadas e de figuras carimbadas da era industrial da modernidade, fazendo emergir "um mundo caótico de conflitos, jogos de poder, instrumentos e arenas que pertencem a duas épocas diferentes, aquela do 'não ambíguo' e aquela da modernidade 'ambivalente'.” (BECK, 1995, p. 28). A 
ação política cotidiana, microscópica e não institucional na modernidade reflexiva amplia e, por vezes, determina a ação política formal. Essas ações fragmentadas e aparentemente dispersas e contraditórias representam o cerne da autoprodução das sociedades contemporâneas a partir de suas bases, de suas margens.

Subpolítica (sub-politics), então, significa moldar a sociedade de baixo para cima. Visto de cima, isto resulta na perda do poder de implementação, no encolhimento e na minimização da politica. No despertar da subpolitização há oportunidades crescentes de se ter uma voz e uma participação no arranjo da sociedade para grupos que até então não estavam envolvidos na tecnificação essencial e no processo de industrialização: os cidadãos, a esfera pública, os movimentos sociais, os grupos especializados, os trabalhadores no local de trabalho. (BECK, 1995, p. 35).

A ação subpolítica implica a capacidade de engajamento de indivíduos e grupos sociais em meio às ambiguidades e contradições características de nosso tempo. $\mathrm{O}$ esgotamento da capacidade do estado-nação em lidar com os mais diversos grupos e minorias a um só tempo liberou as mais diversas forças sociais e colocou sobre os ombros das mesmas a responsabilidade de negociar e construir agendas comuns em meio à multiplicidade de demandas políticas que caracteriza a modernidade tardia (GIDDENS, 1997). Sob essa perspectiva, a produção do comum em meio à explosão de múltiplas formas de existência e demanda social representa o grande desafio das sociedades contemporâneas na construção de um novo modelo de democracia que seja alternativo ao conceito moderno de soberania cujo corpo político deveria ser composto por membros supostamente homogêneos e obedientes a um centro político-decisório. Constituindo-se num contraponto a essa perspectiva de poder político fundamentado na unidade dos governados e na inércia de suas diferenças, o conceito de multidão apresentado por Hardt e Negri (2006) é uma tentativa de compreensão das diversas formas de agenciamento político contemporâneo que combinam coletividade e multiplicidade.

A multidão designa um sujeito social ativo, que age com base naquilo que as singularidades têm em comum. A multidão é um sujeito social internamente diferente e múltiplo cuja constituição e ação não se baseiam na identidade ou na unidade (nem muito menos na indiferença), mas naquilo que tem em comum. [...] A multidão, embora se mantenha múltipla e internamente diferente, é capaz de agir em comum, e portanto de se governar. Em vez de ser um corpo político com uma parte que comanda e outras que obedecem, a multidão é carne viva que governa a si mesma. (HARDT; NEGRI, 2006, p. 140).

A ação coletiva na multidão consistiria na construção de laços solidários e comuns entre indivíduos e grupos sociais sem que isso resulte necessariamente em unidade ou cerceamento das singularidades. Uma renovada e ampliada noção de trabalho passa a ser fundamental para se entender como a multiplicidade de práticas sociais cria vínculos e compartilha elementos em comum. E o papel de articulação entre as diversas atividades produtivas humanas na contemporaneidade caberia, de acordo com Hardt e Negri, ao trabalho imaterial. Ampliando a noção de que o imaterial representaria apenas a produção intelectual, os autores enfatizam o caráter biopolítico das formas produtivas imateriais que combinam conhecimento, linguagem e afeto para produzirem concretas relações e formas de vida social. Todas as esferas da produção social cada vez mais necessitam da criatividade, da sensibilidade e do conhecimento compartilhados em amplas redes comunicativas 
disponibilizadas pelas novas tecnologias da informação e da comunicação. Sendo assim, "a hegemonia do trabalho imaterial cria relações comuns e formas sociais comuns de uma forma mais pronunciada que nunca". (HARDT; NEGRI, 2006, p. 156). Isso não significa, entretanto, que o compartilhamento de informações e conhecimentos resulte na uniformização das diferentes atividades laboriosas. Significa que a proliferação de ações colaborativas entre indivíduos e grupos sociais para os mais diversos fins e nas mais diversas escalas espaçotemporais, em meio às múltiplas formas de produção e reprodução da vida social tecidas em redes de relacionamento e compartilhamento, demonstra a plausibilidade da coexistência entre singularidade e comunidade nas ações políticas.

As novas redes biopolíticas, que possibilitam a construção colaborativa e o compartilhamento de informações e conhecimentos e a própria produção e reprodução da vida social, também estão redefinindo as fronteiras entre produtivo e improdutivo. A hegemonia do trabalho imaterial nas sociedades do capitalismo tardio, ao mesmo tempo em que constrói barreiras e estabelece assimetrias nos diferentes espaços-tempo, valoriza diferentes habilidades e formas de inteligência, inserindo-as nos novos circuitos de produção de riquezas. Nesse aspecto, pobres, subempregados, trabalhadores sazonais e migrantes estão cada vez mais ativos na produção biopolítica. Mais do que vítimas da opressão do capitalismo global, esses grupos sociais, por terem menos a perder do que outros e por serem cotidianamente forçados a viver de sua criatividade, estão menos sujeitos aos padrões de existência socialmente instituídos. Além disso, a instabilidade, a inventividade e a mobilidade desses grupos representam uma ameaça efetiva aos poderes e as formas de controle globalmente difundidos.

Sua mobilidade e sua partilha são uma ameaça constante a desestabilização das hierarquias e divisões globais de que depende o poder capitalista global. Eles se esquivam pelas barreiras e cavam túneis que enfraquecem as muralhas. Além disso, essas classes perigosas estão permanentemente perturbando a constituição ontológica do Império: em cada interseção de linhas de criatividade ou de fuga, as subjetividades sociais tornam-se mais híbridas, misturadas e miscigenadas, escapando ainda mais aos poderes fusionais de controle. (HARDT; NEGRI, 2006, p. 185-186).

A lógica da multidão, em que subjetividades subversivas são produzidas e reproduzidas nas malhas do próprio sistema, criando novos nós, desatando antigas amarras e se constituindo como uma produção alternativa da vida social, coaduna-se com a perspectiva de Walter Mignolo (2004) de que a partir do confronto aberto entre diferentes cosmologias locais - sejam elas hegemônicas, subalternas, de maior ou menor amplitude geográfica - abrese a possibilidade de emergência de discursos e práticas sociais marginalizados que reivindicam a centralidade de suas produções e intentam descontruir a suposta universalidade das narrativas gestadas nas regiões centrais dos impérios coloniais modernos. A partir das situações dialógicas entre a subalternidade e a dominação possibilitadas pela diferença colonial, emerge um modo fragmentado de enunciação, de produção de saberes, denominado de pensamento liminar (cf. MIGNOLO, 2004, p. 11), que permite a compreensão do sistema colonial moderno pela perspectiva dos subalternizados.

De acordo com Mignolo, a dicotomia entre epistemologia e hermenêutica - que, respectivamente, são os fundamentos das ciências e das humanidades na cultura acadêmica desde o advento da modernidade - resultou em formas disciplinarizadas de produção de conhecimento que colocaram para fora de seus limites os diferentes saberes produzidos nas margens externas do sistema colonial moderno (África, América, Ásia e Caribe). Como contraponto a esse modelo disciplinar, seletivo e excludente, a gnose abarcaria as diversas 
formas de produção de conhecimento que estariam além da divisão acadêmica entre ciência e humanidades e além da divisão entre os saberes legitimados pela razão moderna e os saberes construídos como irracionais, sem a chancela dos procedimentos científicos ou sem compromisso com seus regimes de verdade (cf. MIGNOLO, 2004, p. 33-34). Se apropriando da noção de gnose e constituindo a mesma como fundamento para a construção de um conhecimento fronteiriço, nômade e avesso às territorializações típicas da produção acadêmica moderna, Mignolo afirma que

A gnose liminar, enquanto conhecimento em uma perspectiva subalterna, é o conhecimento concebido das margens externas do sistema mundial colonial/moderno; gnosiologia marginal, enquanto discurso sobre o saber colonial, concebe-se na intercessão conflituosa de conhecimento produzido na perspectiva dos colonialismos modernos (retórica, filosofia, ciência) e do conhecimento produzido na perspectiva das modernidades coloniais na Ásia, África, nas Américas e no Caribe. (MIGNOLO, 2004, p. 33).

É na incerteza das margens que a gnose se coloca como um poderoso instrumento de legitimação de formas subalternizadas de conhecimento que se apropriam, desafiam e desestabilizam formas hegemônicas de pensamento e deslocam-se da posição de objeto de estudo para a de novos loci de enunciação. Esses novos lugares de enunciação multiplicam-se nas intercessões entre histórias locais associadas a projetos globais e a histórias locais de menor amplitude espaço-temporal e podem constituir-se em epistemologias que politizem a produção do conhecimento, permitindo que o sujeito seja afetado pelo objeto e sobrepondo o desejo de mudança social ao desejo de verdade. Com efeito, ao produzir múltiplos e semoventes terrenos epistemológicos fora da lógica territorial moderna e de seus universalismos, "o pensamento liminar, na perspectiva da subalternidade, é uma máquina para a descolonização intelectual, e, portanto, para a descolonização política e econômica". (MIGNOLO, 2004, p. 76).

Com base nessa resumida descrição acerca de uma contemporaneidade marcada por políticas subterrâneas, múltiplas e ao mesmo tempo comunais e produtoras de saberes liminares e ideologicamente orientados, passamos agora a tratar de uma ampla perspectiva acerca de práticas de significação denominada episteme do letramento. Para tanto, exploramos a seguir a literatura recente acerca dos modos contemporâneos de produção de sentido com o intuito de verificar como a expansão de diferentes práticas de letramento, advindas de diferentes loci de enunciação, tem abalado os modelos hegemônicos de construção de conhecimento e de subjetividades. Sob a ampla noção da episteme do letramento, pretendemos abordar os múltiplos significados construídos nos diversos espaços-tempo da globalização recente - sobretudo aqueles propiciados pelas novas tecnologias da informação e da comunicação - que fomentam formas de ativismo político nas quais performances de gênero, classe, raça e sexualidade são interseccionalizadas e constituem-se em emergentes projetos políticos não comprometidos com a lógica universalista da modernidade.

\section{Episteme do letramento: a expansão das práticas de significação na contemporaneidade}

Conforme Brockmeier e Olson (2009), com a revolução digital dos anos 80 do século passado, a popularização do computador e da internet e o advento de uma economia de informação em rede, todos nós, em maior ou menor grau, estamos envolvidos em práticas de leitura e escrita. Hoje em dia, a gama de fenômenos associados a letramento, além de 
dificultar uma definição clara e circunscrita desse conceito, implodiu a noção de letramento associada a um específico grupo social, gênero, nível de escolarização e postura intelectual.

Letramento não tem apenas se tornado essencial para todas as fundamentais condições sociais, econômicas e políticas sob as quais nós vivemos, ele também tem se tornado inextricavelmente associado a nossas vidas privadas ou psicológicas, nossos diários, nossas confissões e nossos últimos desejos e testamentos. Tão profundo é nosso envolvimento no letramento que tais conceitos como escrita, leitura e texto têm se tornado conceitos itinerantes, metáforas teóricas e estenografias metodológicas que têm facilmente cruzado limites entre disciplinas e discursos. (BROCKMEIER; OLSON, 2009 , p. 4, tradução nossa).

Essa amplitude transdisciplinar das práticas de letramento impede que as mesmas sejam reduzidas a um paradigma das ciências humanas ou fiquem circunscritas à produção acadêmica. Embora os letramentos envolvam inúmeras e específicas práticas semióticas e produzam uma infinidade de efeitos sociais que não podem ser ontologicamente capturados, há laços e relações em meio a essa diversidade que não podem ser desprezados e que, segundo Brockmeier e Olson (2009, p. 5), podem ser situados num abrangente discurso cultural denominado episteme do letramento. Sob a ampla perspectiva da episteme do letramento, não há espaço para a consagrada epistemologia moderna e seus procedimentos fundamentados na investigação das supostas condições universais da natureza que tornariam possível o desvelamento de verdades. Também não haveria, nesse sentido, um a priori ontológico do conhecimento empírico e sim um a priori histórico que regimenta a produção, a legitimação e as formas de difusão do conhecimento.

Para Kant, o termo a priori denota o que é considerado uma dimensão transcendental do conhecimento humano, aquelas categorias que não podem ser derivadas da experiência porque elas são necessariamente precondições da experiência em si mesma. (...) Para Foucault, entretanto, aquelas categorias (e discursos, como ele coloca, aos quais elas pertencem) são históricas, associadas ao tempo e ao mundo concreto assim como aos modos de ação e de entendimento. Em vez de reivindicarem o status de condições universais e meramente categóricas (isto é, intelectuais), elas chamam a atenção para o contexto cultural em que ideias, instituições e práticas emergem. (BROCKMEIER; OLSON, 2009, p. 7, tradução nossa).

O historicamente a priori de Foucault contradiz os discursos modernos que atribuem transcendência a determinadas categorias, pois estas surgem, são legitimadas e abandonadas na concretude da vida social. Sob esse argumento, o letramento não deve ser visto como meramente uma habilidade, prática ou conteúdo universal a ser aprendido indistintamente em todos os espaços-tempo. Compreender o letramento como uma episteme implica compreender que toda prática de letramento está sob um enquadre sócio-histórico que regimenta suas formas, conteúdos, usos e efeitos sociais. Além disso, isso implica na dissolução de dois mitos seculares gestados pela lógica fonocêntrica: a escrita é uma forma particular de linguagem associada a discursos e práticas específicos; com efeito, estando sujeita à história, a escrita também não é uma representação secundária da fala, mas uma prática de letramento dentre outras. Brockmeier e Olson (2009, p. 14-15) reforçam a crítica ao fonocentrismo ecoando a obra de Jacques Derrida. O filósofo franco-argelino compreende o fonocentrismo não como um erro intelectual, mas como um projeto moral ancorado na concepção de escrita como uma mera extensão da voz - a linguagem natural - e, por conseguinte, como uma neutra tecnologia 
representacional capaz de espelhar transparentemente profundas verdades e significados presentes na mente humana. A primazia da voz sobre a escrita (fonocentrismo) associada a primazia da mente sobre o corpo (logocentrismo) fundamentam uma visão de linguagem como sistema abstrato, fechado, internamente regulado e imune às transformações sociais. Essa suposta separação entre um mundo sensível (material) e um mundo inteligível (mundo dos significados) e a consequente crença na separação entre a linguagem e o mundo concreto é cada vez mais desafiada na contemporaneidade pela emergência de múltiplas práticas de letramento e suas múltiplas formas de construção de significado. Nesse sentido, "a episteme do letramento não pode ser explicada apenas dentro dos confins acadêmicos e teóricos, mas precisa ser situada dentro das trajetórias das abrangentes transformações sociais, culturais e tecnológicas". (BROCKMEIER; OLSON, 2009, p. 15, tradução nossa).

O surgimento e a banalização de tecnologias da comunicação e da informação no século XX - incluindo o telefone, o rádio, a TV e a revolução eletrônica nos anos 70, 80 e 90 - vão impactar decisivamente na expansão de novas e específicas práticas de letramento. Contudo, isso não significa que há uma relação de causa e efeito entre essas tecnologias, os novos modos culturais de comunicação e a crescente importância do letramento na cultura ocidental, pois são fenômenos sobrepostos e inseparáveis. Os novos modos de comunicação, os letramentos advindos da revolução midiática, as ações de organismos nacionais e transnacionais com o intuito de difundir habilidades de letramento supostamente universais e a emergência de novas áreas de conhecimento (Estudos culturais, Estudos da Informação, Comunicação, Estudos da Mídia, etc.) vão em conjunto fomentar um debate transdisciplinar acerca dos múltiplos sistemas de signos e de significação advindos da revolução digital. Juntamente com as críticas feitas aos dogmas fonocêntricos e logocêntricos, esses debates transdisciplinares vão se configurando como fundamentais para a superação das concepções modernas da linguagem e, especificamente, da escrita.

O novo foco sobre a mediação simbólica (ou mediação semiótica) da cultura e do pensamento - com o letramento sendo um modo crucial dentre outros modos dessa mediação - parece ser uma avançada versão do esforço para superar o Sprachvergessenheit tradicional (isto é, o esquecimento da linguagem) na filosofia e nas ciências humanas. Este esforço também tem agora também incluído superar schriftvergessenheit (isto é, o esquecimento da escrita). (BROCKMEIER; OLSON, 2009, p. 17, tradução nossa).

É a imersão dos novos modos de comunicação e seus discursos e significados na concretude da vida humana que está ajudando o Ocidente a superar o esquecimento da linguagem e a colocá-la como uma prática fundamental para a transformação das sociedades da modernidade tardia (GIDDENS, 1997). Entretanto, a posição central ocupada pela linguagem na contemporaneidade expôs a suscetibilidade da mesma à história e aos jogos de poder específicos de cada contexto social. Isso implica dizer que práticas hegemônicas de letramento, como as associadas à leitura e à escrita, não podem ser generalizadas a qualquer espaço-tempo como se fossem instrumentos universais para a transformação ou o desenvolvimento social, pois "letramento deve ser visto como uma atividade envolvida em práticas sociais e culturais em vez de um déficit ou insuficiência do educando para ser remediado por pacotes prontos de conhecimentos e habilidades" (OLSON; TORRANCE, 2001, p. xii, citado por BROCKMEIER; OLSON, 2009, p. 18, tradução nossa). As múltiplas práticas de produção de significados ou os multiletramentos, nesse aspecto, devem ser compreendidos a partir da abordagem dos regimes de crenças e de poder em que estão imersos e a partir da percepção de como essas profusas formas de significação impactam esses regimes. 
Em oposição à visão universalista e atemporal do letramento e fundamentado numa abordagem que "foca sobre os significados e usos cotidianos do letramento em específicos contextos culturais" (STREET, 2009, p. 336-337, tradução nossa), Street estabelece a distinção entre dois modelos de letramento: o autônomo e o ideológico. O modelo autônomo pressupõe a primazia de capacidades técnicas e habilidades de letramento em relação às práticas sócio-históricas. Sob esse aspecto, esse modelo "mascara suposições culturais e ideológicas que subjazem o mesmo e que podem ser apresentadas como se fossem neutras e universais" (STREET, 2009, p. 337, tradução nossa), cabendo ao participante de um evento de letramento desenvolver específicas capacidades cognitivas supostamente predeterminadas e alheias às práticas e crenças em jogo. $\mathrm{O}$ modelo ideológico - perspectiva defendida pelo autor - "oferece uma visão mais culturalmente sensível das práticas de letramento de como eles variam de um contexto a outro" (STREET, 2009, p. 337, tradução nossa), compreendendo letramento como uma prática social situada e fundamentada por princípios epistêmicos socialmente construídos e imersos em relações de poder que posicionam desigualmente os participantes e os recursos sociolinguísticos que dispõem. Com efeito, sob o modelo ideológico, não basta reconhecer a legitimidade e a heterogeneidade de diferentes práticas de letramento se as assimetrias sociais que subjazem as mesmas forem negligenciadas.

Como Luke (1996) argumentou ao criticar a abordagem do gênero australiano para a pedagogia do letramento, não há gêneros intrínsecos de poder; em vez disso, aqueles com o poder para nomear e definir podem mudar o que conta como um poderoso gênero incluindo o que conta como letramento. A etnografia do letramento, então, deve oferecer relatos não apenas das ricas formas culturais e situadas práticas de letramento, mas também dos amplos, mais politicamente carregados relatos de estruturas de poder que definem e ranqueiam tais práticas." (STREET, 2009, p. 339, tradução nossa).

Compreender as práticas locais de letramento sem situá-las em amplas escalas espaço-temporais pode colocar a interpretação das mesmas sob uma perspectiva fundamentada no modelo autônomo de letramento no qual os significados são supostamente fixos e antecedem ao social. Conforme Street, é necessário, portanto, manter a sensibilidade etnográfica para a interpretação de diferentes formas locais de comunicação e de letramento incluindo as formas multimodais de letramento da contemporaneidade - e ao mesmo tempo contemplar as malhas que estas tecem em conjunto com vastas estruturas sociais. Na visão do autor, isso implica considerar também que as práticas comunicativas imersas na globalização estão complexificando o que conta como significado em cada evento social, pois práticas locais de letramento cada vez mais envolvem e, por vezes, transformam significados disseminados globalmente, desmistificando suas restrições geográficas e semióticas (cf. STREET, 2009, p. 341).

É a partir desse cenário de expansão de diferentes letramentos - de diferentes cosmovisões - que se deve compreender a emergência, a circulação de múltiplas e entrecruzadas formas de produção de significados e de interseccionalizadas performances identitárias. Nos espaços típicos da era global recente, esses processos multisemióticos de constituição efêmera de realidades e subjetividades têm impactado decisivamente tanto na constituição e manutenção de relações de poder hegemônicas quanto na transformação das mesmas, possibilitando maior equilíbrio na relação entre as forças em jogo. 


\section{Letramentos contemporâneos: desigualdade e mudança social}

Em 1994, um grupo de pesquisadores se reuniu na pequena cidade de Nova Londres para debater sobre os rumos da pedagogia do letramento - sobretudo o ensino de língua - em meio ao cenário de diversidade cultural que emergiu paralelamente à intensificação dos encontros entre culturas de distintas localidades na globalização recente. A percepção de que o objeto de aprendizagem - o inglês, no caso - estava sendo significativamente modificado pelas rápidas mudanças nas tecnologias comunicacionais criou a necessidade de um novo termo que contemplasse a multiplicidade de canais midiáticos e a crescente diversidade cultural e linguística. $\mathrm{O}$ termo multiletramentos foi escolhido por se compreender que o mesmo incluía dois importantes argumentos associados à ordem global emergente: "o primeiro argumento engaja-se com a multiplicidade de canais de comunicação e mídia; o segundo com a crescente saliência da diversidade linguística e cultural". (COPE; KALANTZIS, 2000, p. 5, tradução nossa).

$\mathrm{O}$ conceito de multiletramentos enfatiza a multiplicidade textual dos novos tempos negligenciada pela pedagogia convencional do letramento. $\mathrm{O}$ mero letramento estaria preso a uma visão de língua como sistema estável internamente regulado, que privilegia uma específica e hegemônica norma linguística associada ao conceito de estado-nação e que se constitui num rigoroso sistema classificatório capaz de discernir seu uso correto dos usos desviantes. Em oposição a essa perspectiva,

A pedagogia dos multiletramentos [...] foca sobre os modos de representação mais amplos do que a língua isolada. Esses diferem de acordo com a cultura e o contexto e têm específicos efeitos cognitivos, culturais e sociais. [...] Multiletrametos também criou um diferente tipo de pedagogia na qual a linguagem e outros modos de significado são dinâmicos recursos representacionais, constantemente sendo refeitos por seus usuários para alcançar seus variados propósitos culturais. (COPE; KALANTZIS, 2000, p. 5 , tradução nossa).

Seguindo a lógica da pedagogia dos multiletramentos, o significado na era global é produzido crescentemente em formato multimodal, combinando textos, aspectos áudiovisuais, espaciais, comportamentais, etc. Esse caráter múltiplo e imprevisível das produções de significados põe cada vez mais em xeque a ideia de que existem padrões pré-estabelecidos de práticas de letramento e seus efeitos na sociedade. Além disso, a globalização está colocando a diversidade linguística e cultural em nossas vidas diárias e locais, corroendo engessadas visões de língua e de cultura. O inglês, por exemplo, na mesma medida em que é considerado uma língua global, está se fragmentando em múltiplos ingleses, diferenciados por aspectos como sotaque, nacionalidade, atividades técnico-profissionais, etc. (cf. COPE; KALANTZIS, 2000, p. 6). Mais do que reproduzir os padrões de língua, cultura, comportamento e ideologias subjacentes da globalização, as pessoas em suas localidades estão se apropriando criativamente das mesmas e reinventando suas práticas sociais sob a dinâmica da multidiversidade de nosso tempo.

Sob a perspectiva dos multiletramentos, ser letrado passa a significar a possibilidade de agência social e de construção criativa e crítica das realidades e dos futuros sociais. $\mathrm{O}$ engajamento cotidiano e, por vezes, inevitável em práticas de letramento de todo tipo torna fundamental a compreensão de que estamos ao mesmo tempo reproduzindo e transformando a vida social. 
O conceito chave que nós desenvolvemos é aquele do Design, em que nós somos herdeiros de padrões e convenções de significado enquanto ao mesmo tempo ativos designers de significados. E, como designers de significados, nós somos designers de futuros sociais - futuros locais de trabalho, futuros públicos, futuras comunidades. (COPE; KALANTZIS, 2000, p. 7, tradução nossa).

É preciso lembrar, entretanto, que o acesso aos recursos tecnológicos que possibilitam vivenciar as práticas de multiletramentos e desfrutar de seus efeitos sociais tem sido marcado pela desigualdade. Divisão digital é a expressão usada para descrever as diferenças no acesso aos recursos e ambientes digitais entre países desenvolvidos e subdesenvolvidos, entre ricos e pobres, entre homens e mulheres e entre aqueles que usam tais recursos para se engajarem politicamente na vida social e aqueles que não usam para esse fim (cf. DOBSON; WILLINSKY, 2009, p. 295). Além disso, não é apenas a ausência de recursos tecnológicos e econômicos a única barreira que impossibilita o acesso aos textos eletrônicos, pois a hegemonia do inglês nos ambientes on-line também tem se constituído numa forma de exclusão de vastos contingentes populacionais em diferentes países que não dominam sequer o uso instrumental dessa língua. As tentativas de estados, organizações intergovernamentais e não governamentais para reduzir tais desigualdades, no entanto, tem se pautado pela lógica da grande divisão entre culturas orais e culturas letradas - que representaria uma suposta divisão entre culturas primitivas e civilizadas - e pela compreensão do letramento digital como um conjunto de universais competências e habilidades técnicas a serem apreendidas indistintamente em variados espaços-tempo. Conforme vimos acima, tal perspectiva não é ratificada pelos recentes estudos acerca do fenômeno das práticas de letramento que consideram que as mesmas - independentemente de sua natureza ou origem sócio-cultural não possuem valor cognitivo intrínseco e não podem ser generalizáveis a qualquer contexto.

Em tempos de globalização, fica evidente o descompasso entre práticas e formas de produção de significado oriundas de conflitantes economias de letramento ${ }^{1}$ proporcionado pela intensa circulação de pessoas e de textos em nossa era. Esses encontros e desencontros de práticas de letramento justapõem-se a outro fenômeno da contemporaneidade que é o da intensificação da dependência contextual das práticas linguísticas - referentes aos aspectos sociais, políticos, culturais e econômicos subjacentes às mesmas - e o da complexificação das noções tradicionais de leitura e escrita com o advento de variadas e entrecruzadas práticas de significação. Torna-se, portanto, imperioso pensar tais práticas não apenas em termos de leitura e escrita, mas em termos do repertório de recursos sociolinguísticos que as pessoas possuem e se utilizam nos espaços-tempo em que circulam.

Um repertório é a totalidade de recursos comunicativos, conhecimentos sobre sua função e suas condições de uso, e isso representa um domínio muito concreto da vida social. Pensando sobre repertórios nos força a

\footnotetext{
${ }^{1}$ De acordo com o dicionário escolar da língua portuguesa da Academia Brasileira de Letras (2008, p. 463), dentre outras definições, o verbete economia significa "ciência que tem por objeto o conhecimento dos fenômenos de produção, circulação e distribuição de riquezas e bens materiais" e "conjunto de atividades de produção, circulação e distribuição de riquezas e bens materiais de um país ou região". Por contiguidade a essas definições, utilizamos o termo economia de letramento para abarcar os processos de produção, circulação e distribuição de significados engendrados e legitimados em específicas espaço-temporalidades. Compreendemos, entretanto, uma específica economia de letramento como uma produção sempre provisória, susceptível ao embate com outras economias de letramento e sujeita a interseção ou ao entrecruzamento com as mesmas.
} 
abandonar noções totalizantes no campo da linguagem e da comunicação, e situá-las com termos que identificam práticas específicas e reais. A variedade de fatores que nós precisamos considerar ao analisar letramento, consequentemente é expandida e agora inclui fatores sociais, culturais, históricos e políticos. (BLOMMAERT, 2007, p. 8-9, tradução nossa).

O acesso seletivo a sofisticados e valorizados recursos sociolinguísticos entre indivíduos e grupos sociais da mesma sociedade ou de sociedades distintas demonstra o quanto diferenças entre práticas de letramento são perpassadas por questões de poder e desigualdade. Os contextos sociais globais são altamente regimentados por processos de filtragem e de estratificação de recursos e repertórios que posicionam os mesmos em escalas assimétricas. Sob esse aspecto, "letramento é organizado em regimes de letramento, em estruturas de distribuição, acesso, valor e uso que são intimamente associados à constituição geral das sociedades". (BLOMMAERT, 2007, p. 9, tradução nossa). A intensa circulação e fricção de textos na era global recente impôs sobre o campo dos estudos do letramento a necessidade de se debruçar sobre os efeitos contextuais da mobilidade nas práticas comunicativas mais efêmeras, pois os regimes de letramento de cada espaço-tempo redefinem e estratificam os repertórios e recursos que circulam sob os mesmos.

Textos podem viajar facilmente, mas o sistema de uso, valor e função em que eles foram produzidos usualmente não viaja com eles. A globalização impôs uma nova matriz sobre nossa análise: nós estamos agora encarando a tarefa de conceber uma etnografia, não da localidade, mas da transferência, da mobilidade - não do produto mas do processo, e não em uma ecologicamente descrita comunidade mas entre comunidades. (BLOMMAERT, 2007, p. 10, tradução nossa).

As práticas de letramento de grupos sociais minoritários são marcadas pela restrição de mobilidade, pela perda de voz, valor e função na transposição de espaços-tempo e, portanto, estão sujeitas a constrangimentos e envolvidas em relações de poder. Blommaert (2007) denomina de letramentos de raiz as práticas comunicativas e de produção de significados típicas de grupos sociais ou regiões periféricas. Para uma melhor compreensão dos textos produzidos em contextos de letramentos de raiz, é fundamental a adoção de uma etnografia que se debruce sobre a construção formal desses textos, contemplando seus aspectos linguísticos e estilísticos, e sobre as estruturas de poder que regulam tal processo (cf. BLOMMAERT, 2007). Além de esmiuçar as condições histórico-sociais de produção dos textos de letramentos de raiz, é de similar importância atentar para a complexidade das atividades humanas em que estão inseridos e para as condições de circulação e os modos diferenciados de apropriação dos mesmos em variados contextos, pois todo texto deve ser compreendido como produto intrínseco e inseparável de suas contíguas práticas sociais.

Não há texto sem contexto: todo texto revela fatores de seu singular contexto de produção assim como do potencial que ele possui para mover-se através de contextos. Assim, todo texto que nós não temos uma informação contextual poderá ser analiticamente contextualizado. O fato de nós não conhecermos seus autores, a linguagem na qual ele foi produzido, sua função e audiência original, sua aceitação por aquela audiência - tudo isso não significa que o texto não possui contexto; isso significa que nós temos que contextualizá-lo, preencher suas lacunas contextuais por meio de uma rigorosa interpretação contextual. (BLOMMAERT, 2007, p. 19, tradução nossa). 
Tal proposta de etnografia textual ancora-se num método investigativo denominado por Carlos Ginzburg (1989) de paradigma indiciário cuja tradição privilegia a indução em vez da dedução, partindo da interpretação de fatos empíricos e de casos particulares para reconstruir contextos mais amplos. Essa perspectiva pode ser válida para a reconstrução das inteligibilidades próprias de textos produzidos em contextos de letramentos de raiz cujos padrões de funcionamento são considerados incoerentes, irracionais e sem significado pelas lógicas textuais consagradas no Ocidente. Juntamente com esse paradigma conjectural, a etnografia proposta por Blommaert apropria-se da filologia desenvolvida por Hymes (2003) para construir uma estratégica micro-analítica que investiga os padrões e princípios organizacionais caros a um texto e que "refletem os métodos empregados pelo autor na construção textual" (BLOMMAERT, 2007, p. 22, tradução nossa). Esses padrões de construção textual, compreendidos também como ideologias linguísticas, orientam crenças específicas dos usuários de recursos linguísticos sobre o que são tais recursos, qual a finalidade do emprego dos mesmos e "o que seu uso nos diz sobre o ato de comunicação e sobre aqueles que performam os mesmos". (BLOMMAERT, 2007, p. 22, tradução nossa). O ganho de tal abordagem está na possibilidade de fazer com que textos produzidos por indivíduos ou grupos minoritários sejam compreendidos a partir de seus próprios termos e lógicas textuais, a partir de suas próprias vozes.

Ecoar as vozes implícitas dos textos subalternizados, além de um compromisso político dos etnógrafos do letramento, é um grande desafio que só pode ser vencido na medida em que se reconhece que a globalização recente é marcada mais pelas desigualdades que produz e sustenta do que pela uniformidade. Isso implica dizer também que a intensificação dos conflitos entre letramentos locais e hegemônicos/globais, além de não resultar necessariamente em submissão e padronização de práticas sociais locais, pode produzir formas inovadoras de ação político-social que combinam discursos e significados distintos e que podem desestabilizar estruturas de poder vigentes.

Souza (2008) chama a atenção para importância de se abordar práticas de letramento no mundo atual como processos em permanente construção e reconstrução cuja dinâmica impossibilita a territorialização e a reificação das mesmas. O exercício de reconhecimento de múltiplas culturas e múltiplos letramentos em meio às complexas e hibridas sociedades contemporâneas deve ser acompanhado do abandono das noções circunscritas e estáveis de cultura e letramento e de uma minuciosa investigação acerca do entrecruzamento dos mesmos.

Em contextos tais como os dos letramentos indígenas no Brasil ou aqueles dos letramentos computacionais na África do Sul como descrito por Prinsloo (2005), letramento consiste na introdução de uma nova tecnologia ou meio de produção de significado, tais como escrita alfabética ou hardware e software de computador, em comunidades onde tais tecnologias não existiam anteriormente. $\mathrm{O}$ caráter trans de tal situação repousa no atravessamento de fronteiras que ocorre quando essas novas tecnologias ou meios semióticos passam de uma prévia existência em uma comunidade e suas práticas para uma nova comunidade que precisa absorvê-la ou adaptar-se a ela. (SOUZA, 2008, p. 195, tradução nossa).

Sob uma perspectiva de fluxo e fronteiriça, o autor alerta para a necessidade dos estudos de letramento se preocuparem menos com a pluralidade cultural e linguística produzida nas comunidades afetadas pelas novas tecnologias comunicacionais e mais com os processos resultantes dos fluxos de significados entre contextos. É fundamental, nesse 
aspecto, focar "sobre como as relações de similaridade ou diferença entre as duas comunidades (de origem e de chegada) afetam as práticas de letramento desenvolvidas" (SOUZA, 2008, p. 195, tradução nossa), atentando para os processos - pacíficos ou conflituosos - de manutenção, abandono ou transformação dos significados em circulação. Com efeito, é a partir de uma observação mais acurada das assimetrias estabelecidas nos encontros e nas interseções entre práticas e culturas de letramento que se pode perceber as formas e estratégias de dominação, resistência e transformação social em jogo.

Fundamental para a compreensão dos efeitos resultantes das intersecções entre distintas economias de letramento é o uso criativo e político das tecnologias. Entretanto, assim como a linguagem, há uma tradição secular que concebe a tecnologia como algo neutro, independente do mundo social e do âmbito exclusivo das ciências naturais. Acerca disso, Sádaba e Gordo afirmam que:

Ainda prevalece a concepção mitológica e naturalizante que coloca o par ciência-técnica em um pedestal elevado, como domínio extrapolítico regulado por leis naturais e associais. Frente a ela, a perspectiva que aqui sugerimos objetiva analisar tecnos como um âmbito político, as ciências aplicadas como um espaço onde se dirimem relações de poder e o conhecimento especializado como um lugar conflitivo onde numerosos agentes lutam, constroem, deliberam e interagem. (SÁDABA; GORDO, 2008, p. 10, tradução nossa).

O advento e a disseminação das tecnologias são impensáveis sem os efeitos políticosociais que produzem e sem a influência efetiva dos agentes sociais, "pois qualquer intervenção política requer a incorporação da tecnologia como espaço de operações e como horizonte a transformar, enfim, como um espaço em disputa". (SÁDABA; GORDO, 2008, p. 10, tradução nossa). Isso implica considerar que as tecnologias não são apenas instrumentos de controle à disposição de organizações estatais, supranacionais ou mercadológicas, pois estão intimamente relacionadas aos movimentos sociais e são a todo instante apropriadas e reconfiguradas pelos mesmos. As tendências limitadoras e totalitárias dos meios técnicos, compreendidos também como formas de governo, nem sempre se confirmam na medida em que eles só funcionam imbricados na vida social e, portanto, estão sujeitos a instabilidade desta. Sob essa perspectiva, as tecnologias não se adicionam meramente às práticas de sustentação ou transformação social. Elas moldam culturalmente as ações coletivas e são eventualmente moldadas por estas.

Em um instigante artigo sobre relações tecnosexuais, Cleminson e Gordo (2008) demonstram como a apropriação de tecnologias, desde o medievo europeu até o advento dos sites de relacionamento pessoal na virada do século XX para o XXI, fomenta a produção de novas formas de sociabilidade que escapam ao controle técnico-racional e possibilitam a emergência de práticas sexuais - ou tecnosexuais, como designam os autores - e de ações políticas subversivas. Uma demonstração de que as técnicas de governo não apenas domesticam, mas também incitam novas performances identitárias é a investigação que os autores fazem sobre a constituição dos mosteiros duplos na baixa Idade Média. Nesses espaços fechados, altamente normatizados e desenvolvidos para produção de corpos alheios à vida mundana, monges e monjas criavam meios clandestinos, rotas subterrâneas para comunicar-se entre si e com o mundo secular. Assim, redes de intercâmbio eram estabelecidas possibilitando, além de encontros amorosos, intensas trocas técnico-culturais que desafiavam a disciplina corporal idealizada para a vida monacal e as verdades hegemônicas da Igreja medieval. 
Os moinhos medievais, conforme Cleminson e Gordo (2008), constituíram-se também como espaços permeados pela perturbadora associação entre os âmbitos técnico e social. Construídos para maximizar a exploração dos senhores de terras sobre os camponeses, os moinhos eram lugares onde se estabeleciam interações entre indivíduos de diferentes ordens sociais e perspectivas culturais, onde assimetrias sociais eram expostas e, principalmente, onde "se forjavam novas relações e se acolhia o outro, seja como figura forasteira ou em forma de novos intercâmbios técnicos, sexuais e culturais" (CLEMINSON; GORDO, 2008, p. 36, tradução nossa). Para as autoridades eclesiásticas e seculares, esses intercâmbios de práticas, ideias e corpos diversos - encontros potencialmente capazes de produzir formas interseccionalizadas de existência - faziam dos moinhos ameaças concretas à ordem social e aos valores vigentes.

Em certo sentido, o moinho poderia considerar-se um centro de encontro que rivalizava com a Igreja em termos de seu poder de atração de multidões, como lugar para facilitar a fofoca e o fluxo de informações, planejar rebeliões e disseminar novas técnicas. [...] Tal mescla de materialidade, regulação religiosa e troca de costumes outorgou ao moinho a dimensão de espaço proibido que abria a possibilidade de um lugar público para a erotização e o comércio, que propiciava os encontros casuais entre membros laicos da sociedade e o clero, entre pessoas de diferentes classes sociais e idades, todos sob o manto das inovações técnicas de marcada natureza comunal. (CLEMINSON; GORDO, 2008, p. 38, tradução nossa).

Os encontros e desencontros entre diversidades subjetivas, a exposição dos conflitos e das assimetrias sociais e, sobretudo, a construção de laços comuns e solidários entre sujeitos de distintas performances de classe, gênero, sexualidade, raça, entre outros - fenômenos que emergem do uso conspiratório e indisciplinar das tecnologias - adquiriram na modernidade tardia proporções nunca antes vistas, penetrando e remodelando todos os espaços-tempo. Nos dias de hoje, como exemplo da expansão contra-hegemônica da técnica, o uso político de redes sociais como o Facebook caracteriza-se pela produção dinâmica e permanente de diferentes e conflitantes demandas através da publicação de postagens, memes e comentários nas páginas pessoais e nos variados grupos privados. Eventos de natureza política emergem, ganham importância e materialidade nesses ambientes virtuais antes mesmo de se disseminarem nas ruas. Movimentos como a greve das/dos professoras/es da rede pública de ensino da cidade do Rio de Janeiro em 2013 confirmam o quanto essas novas tecnologias são subversivamente apropriadas e intrinsecamente relacionadas às práticas tradicionais de luta política. Especificamente nesse movimento, a criação e expansão de um grupo no Facebook (PROFESSORES PCRJ/SME), que hoje conta com mais de 19 mil membros, foi fundamental para que outras demandas - de cunho racial, social, sexual, dentre outras - viessem à tona e se misturassem às agendas específicas das/dos profissionais de educação. Ao acessar os arquivos da página do grupo, vimos a postagem ${ }^{2}$ de uma professora, publicada em 26 de setembro de 2014, compartilhando a experiência de uma colega de trabalho que sempre pedia aos alunos, integrantes de uma turma do $5^{\circ}$ ano do ensino fundamental da rede pública de Nova Iguaçu no Rio de Janeiro, que pintassem o desenho da capa da prova. Em um dia de aplicação da prova, no desenho da capa estavam os personagens da turma da Mônica - que são construídos como crianças brancas - e um dos alunos se dirigiu à professora com os personagens pintados na cor marrom e disse "pintei da minha cor, tá? Cansei desses desenhos diferentes de mim".

\footnotetext{
${ }^{2}$ Disponível em https://www.facebook.com/groups/professores.pcrj.sme/search/?query=desenho\%20da\%20 m $\% \mathrm{C} 3 \% \mathrm{~B} 4$ nica. Acessado em junho de 2017.
} 
Vários foram os comentários - 54 comentários, no total, e 475 curtidas - que elogiaram a atitude do aluno, considerando o gesto simples como uma prova de sua elevada auto-estima e como um protesto contra o apagamento da negritude em produções semióticas como animações ou histórias em quadrinhos para crianças. Em outra postagem ${ }^{3}$, de 25 de outubro de 2015, uma professora começa dizendo que "a cada duas horas uma mulher trabalhadora é assassinada no Brasil [...]”, a associação entre misoginia e preconceito de classe por si só já constitui um movimento de interseccionalização de performances identitárias, pois a autora do post projeta como significado a maior susceptibilidade das mulheres pobres à violência generificada. Na mesma publicação, entretanto, a autora também considera que "para vencer os ricos e poderosos, temos que discutir opressões. As opressões como machismo, racismo e homofobia são utilizadas pelo capitalismo como instrumento de divisão da classe trabalhadora para a burguesia dominar!" Fica aqui manifesta a crença da participante do grupo do Facebook de que a luta de classes só pode ser potencializada se junto a ela forem articuladas questões de raça, gênero e sexualidade. Esses exemplos são amostras emblemáticas de como os sites de relacionamento pessoal passaram a ter uma influência decisiva na construção e nos rumos de diferentes movimentos sociais da atualidade, complexificando suas agendas e reinventando suas formas de atuação.

Os movimentos sociais contemporâneos se valem cada vez mais da combinação criativa entre diferentes economias e tecnologias de letramento para fundamentar suas atividades políticas. Seja através de sites oficiais, páginas em redes de relacionamento ou grupos em aplicativos como o WhatsApp, multiplicam-se as políticas marginais - ou as subpolíticas como assim foram denominadas por Beck (1997) - que impactam de baixo para cima tanto as sociedades quanto seus centros político-decisórios. Essas redes de contrastes e de compartilhamento de práticas e discursos também ajudam a compor um cenário social ambivalente no qual o novo, o velho, a vanguarda e a tradição se chocam, dialogam e também produzem ações coletivas, comunitárias em meio à multiplicidade - ou em meio à multidão (HARDT; NEGRI, 2005). Desses choques e diálogos emergem também práticas de letramentos nômades, fronteiriças, liminares (MIGNOLO, 2000) que transpassam as delimitações do saber e do ser estabelecidas pela modernidade e se constituem em novos loci de enunciação que tornam nebulosos, borrados os limites que separam as regiões periféricas das regiões centrais, reconfigurando a relação entre as mesmas e o ordenamento estabelecido.

\section{Considerações finais}

Nesse pequeno ensaio, procuramos criar inteligibilidade acerca do complexo e amplo tema dos letramentos no contexto das sociedades contemporâneas. Conforme expomos nas linhas acima, somos agentes privilegiados das rápidas e profundas transformações operadas na modernidade tardia que abalam o caráter privado de nossas cotidianas experiências e as inserem em amplas e compartilhadas formas de contestação política. Espontaneamente ou a nossa revelia, participamos de conflitos ideológicos, somos instados a criar sentido sobre os mais variados temas, a tomar decisões e a agir sem ter certeza dos efeitos decorrentes. Nesse tempo em que a incerteza é uma regra, também somos instados a fazer parte de uma multidão de singularidades que, sem as garantias da tradição moderna, é forçada a construir laços de solidariedade entre sujeitos de diversas e, por vezes, conflitantes cosmovisões. Mergulhamos cada vez mais na era do risco e do faça você mesmo, gerando medo, conflitos de toda sorte e a

\footnotetext{
3 Disponível em https://www.facebook.com/groups/professores.pcrj.sme/search/?query=viol\%C3\%AAncia $\% 20$ contra \%20 mulher. Acessado em junho de 2017.
} 
eclosão de variadas oportunidades de reinvenção da vida social. Reinvenção que subrepticiamente vem corroendo por dentro as crenças e os regimes de verdade da modernidade e embaçando os limites entre saberes consagrados por uma tradição acadêmico-científica e saberes subalternizados, caracterizados como míticos ou irracionais.

A expansão das práticas de letramento na modernidade tardia e suas múltiplas formas de atribuição de significado têm intensificado as tensões entre as fronteiras criadas pela modernidade para disciplinar a produção do conhecimento e da vida social e têm abreviado a ruptura das mesmas. Isso não implica apostar no fim das assimetrias entre as práticas de letramento hegemônicas e as subalternizadas, mas sim num movimento contínuo de choque e entrecruzamento das mesmas que vem, por um lado, abalando a crença no caráter neutro e universal de específicos conhecimentos e habilidades e expondo, por outro lado, seu caráter eminentemente ideológico.

Os regimes de letramento definem o que, como, onde, por quem e em que circunstâncias algo deve ser dito, escrito e nos dão a dimensão de que sobre todos os espaçostempo operam formas de controle que posicionam pessoas e seus recursos sociolinguísticos em escalas assimétricas. O fluxo dinâmico de textos e de pessoas propiciado pela globalização recente problematizou ainda mais os conflitos entre economias de letramento e os efeitos sociais decorrentes. Entretanto, a intensa mobilidade de práticas e tecnologias de letramento não é apenas marcada pela reprodução de formas hegemônicas de construção de significados, mas por apropriações críticas e criativas das mesmas. O uso inusitado, cambiante e subversivo de tecnologias e práticas de letramento têm transformado a face dos movimentos sociais e promovido a ascensão de formas de ativismo perpassadas por questões políticas mais abrangentes, demonstrando que dificilmente uma ação política será bem sucedida nos tempos atuais se ignorar as diferentes interseções de gênero, classe, raça e sexualidade que atravessam sua agenda principal. Nesse aspecto, se alguns grupos e indivíduos das gerações atuais ainda reivindicam melancolicamente o retorno da velha política e das tradições sócio-culturais engessadas e circunscritas da modernidade, outros se regozijam e celebram um mundo cada vez mais afeito à instabilidade, à mistura e à mudança.

\section{Referências}

COPE, B.; KALANTZIS, M. Multiliteracies: the beginning of an idea. In: COPE, B.; KALANTZIS, M. (Eds) Multiliteracies: literacies learning and the design of social futures. London: Routledge, 2000, p. 3-8.

BECK, U. A reinvenção da política: rumo a uma teoria da modernização reflexiva. In: BECK, U.; GIDDENS, A.; LASH, S. Modernização reflexiva: política, tradição e estética na ordem social moderna. São Paulo: UNESP, 1997, p. 11-71.

BLOMMAERT, J. Glassroots literacies. Writing, identity in Central Africa. London: Routledge, 2007.

BROCKMEIER, J.; OLSON, D. R. The literacy episteme: from Innis to Derrida. In: OLSON, D. R.; TORRANCE, N. (Orgs.). The Cambridge handbook of literacy. Cambridge: Cambridge University Press, 2009. 
CLEMINSON, R.; GORDO, A. Relaciones tecnosexuales: de los molinos medievales a las páginas de encuentro. In: SÁDABA, I.; GORDO, A. (Coords.) Cultura digital e movimentos sociales. Madrid: Catarata, 2008, p. 25-48.

DICIONÁRIO escolar da língua portuguesa. Academia Brasileira de Letras. São Paulo: Companhia editora nacional, 2008.

DOBSON, T. M.; WILlinSKY, J. Digital Literacy. In: OLSON, D. R.; TORRANCE, N. (Orgs.). Cambridge Handbook of Literacy. Cambridge: Cambridge University Press, 2009, 286-312.

FUKUYAMA, F. O fim da História e o último homem. Rio de Janeiro: Rocco, 1992.

GIDDENS, A. Risco, confiança, reflexividade. In: BECK, U.; GIDDENS, A.; LASH, S. Modernização reflexiva: política, tradição e estética na ordem social moderna. São Paulo: UNESP, 1997, p. 219-234.

GINZBURG, C. Mitos, emblemas, sinais: morfologia e história. São Paulo: Companhia das Letras, 1989.

HARDT, M.; NEGRI, A. Multidão. Rio de Janeiro: Editora Record, 2005.

HOBSBAWM, E. A era dos extremos: o breve século XX. 1914-1989. São Paulo: Companhia das Letras, 1995.

HYMES, D. Now I Know Only So Far: essays in ethnopoetics. Lincoln: University of Nebraska Press, 2003.

MIGNOLO, W. D. Histórias locais/projetos globais: colonialidade, saberes subalternos e pensamento liminar. Belo Horizonte: Editora UFMG, 2003.

OLSON, D. R.; TORRANCE, N. (Eds.) The making of literate societies: literacy and social development. Oxford: Blackwell, 2001, p. x-xiii.

SÁDABA, I.; GORDO, A. La tecnologia es política por otros medios. In: SÁDABA, I.; GORDO, A. (Coords.). Cultura digital e movimientos sociales. Madrid: Catarata, 2008, p. 922.

SOUZA, L. M. Going beyond "here's a culture, here's a literacy". Vision in Amerindian literacies. In: PRINSLOO, M.; BAYNHAN, M. Literacies, Global and Local. Amsterdam: John Benjamins Publish Company, v. 2, 2008, p. 193-213.

STREET, B. Ethnography of writing and reading. In: OLSON, D. R.; TORRANCE, N. (Orgs.). Cambridge Handbook of Literacy. Cambridge: Cambridge University Press, 2009, p. 329-345.

Recebido em: junho de 2017.

Aprovado em: agosto de 2017. 